\title{
Bacterial adhesion characteristics on implant materials for intervertebral cages: titanium or PEEK for spinal infections?
}

\author{
Theresa Krätzig $^{1} \cdot$ Klaus Christian Mende $^{1} \cdot$ Malte Mohme $^{1} \cdot$ Simon von Kroge ${ }^{3} \cdot$ Martin Stangenberg $^{4}$. \\ Marc Dreimann $^{4} \cdot$ Manfred Westphal $^{1} \cdot$ Samira Weisselberg ${ }^{2} \cdot$ Sven Oliver Eicker $^{1}$
}

Received: 31 March 2020 / Revised: 13 December 2020 / Accepted: 16 December 2020 / Published online: 9 January 2021

(c) The Author(s) 2021

\begin{abstract}
Purpose Surgical intervention with intercorporal stabilisation in spinal infections is increasingly needed. Our aim was to compare titanium and polyetheretherketon (PEEK) cages according to their adhesion characteristics of different bacteria species in vitro.

Methods Plates made from PEEK, polished titanium (Ti), two-surface-titanium (TiMe) $(n=2-3)$ and original PEEK and porous trabecular structured titanium (TiLi) interbody cages $(n=4)$ were inoculated in different bacterial solutions, S.aureus (MSSA, MRSA), S.epidermidis and E.coli. Growth characteristics were analysed. Biofilms and bacteria were visualised using confocal- and electron microscopy.

Results Quantitative adherence of MSSA, MRSA, S.epidermidis and E.coli to Ti, TiMe and PEEK plates were different, with polished titanium being mainly advantageous over PEEK and TiMe with significantly less counts of colony forming units (CFU) for MRSA after $56 \mathrm{~h}$ compared to TiMe and at $72 \mathrm{~h}$ compared to PEEK ( $p=0.04$ and $p=0.005)$. For MSSA, more adherent bacteria were detected on PEEK than on TiMe at $32 \mathrm{~h}(p=0.02)$. For PEEK and TiLi cages, significant differences were found after 8 and $72 \mathrm{~h}$ for S.epidermidis $(p=0.02$ and $\mathrm{p}=0.008)$ and after $72 \mathrm{~h}$ for MSSA $(p=0.002)$ with higher bacterial counts on PEEK, whereas E.coli showed more CFU on TiLi than PEEK $(p=0.05)$. Electron microscopy demonstrated enhanced adhesion in transition areas.

Conclusion For S.epidermidis, MSSA and MRSA PEEK cages showed a higher adherence in terms of CFU count, whereas for E.coli PEEK seemed to be advantageous. Electron microscopic visualisation shows that bacteria did not adhere at the titanium mesh structure, but at the border zones of polished material to rougher parts.
\end{abstract}

Keywords Spondylodiscitis $\cdot$ Spinal infection $\cdot$ Biofilm $\cdot$ Bacteria $\cdot$ Intervertebral cages

\begin{tabular}{|c|c|c|c|}
\hline Abbr & & CT & Computed tomography \\
\hline${ }^{\circ} \mathrm{C}$ & Degree Celsius & E.coli & Escherichia coli \\
\hline CFU & Colony forming units & $\mathrm{h}$ & Hours \\
\hline & & $\mathrm{H}$ & Height \\
\hline & & $\mathrm{kV}$ & Kilovolt \\
\hline Samira & rg and Sven Oliver Eicker contributed equally. & $\mathrm{L}$ & Length \\
\hline $\begin{array}{l}\text { Electro } \\
\text { article }\end{array}$ & $\begin{array}{l}\text { entary material The online version of this } \\
\mathrm{rg} / 10.1007 / \mathrm{s} 00586-020-06705-\mathrm{z}) \text { contains }\end{array}$ & $\begin{array}{l}\mathrm{LB} \\
\min \end{array}$ & $\begin{array}{l}\text { Lysogeny broth } \\
\text { Minutes }\end{array}$ \\
\hline
\end{tabular}

supplementary material, which is available to authorized users.

Theresa Krätzig

t.kraetzig@uke.de

1 Department of Neurosurgery, University Medical Centre Hamburg-Eppendorf, Martinistr, 52, 20246 Hamburg, Germany

2 Institute of Medical Microbiology, Virology and Hygiene, University Medical Centre Hamburg-Eppendorf, Hamburg, Germany
3 Department of Osteology and Biomechanics, University Medical Centre Hamburg-Eppendorf, Hamburg, Germany

4 Division of Spine Surgery, Department of Trauma and Orthopaedic Surgery, University Medical Centre Hamburg-Eppendorf, Hamburg, Germany 


$\begin{array}{ll}\text { ml } & \text { Millilitre } \\ \text { MrI } & \text { Millimetre } \\ \text { MRSA } & \text { Magnetic resonance imaging } \\ & \begin{array}{l}\text { Methicillin-resistant Staphylococcus } \\ \text { aureus }\end{array} \\ \text { MSSA } & \begin{array}{l}\text { Methicillin-sensitive Staphylococcus } \\ \text { aureus }\end{array} \\ \text { OD } & \text { Optical density } \\ \text { PBS } & \text { Phosphate-buffered saline } \\ \text { PEEK } & \text { Polyetheretherketon } \\ \text { rpm } & \text { Rounds per minute } \\ \text { S.aureus } & \text { Staphylococcus aureus } \\ \text { SD } & \text { Standard deviation } \\ \text { SEM } & \text { Scanning electron microscopy } \\ \text { S.epidermidis } & \text { Staphylococcus epidermidis } \\ \text { Ti } & \text { Polished titanium plate } \\ \text { TiLi } & \text { Porous trabecular cantered titanium cage } \\ \text { TiMe } & \text { Two surface titanium mesh plate } \\ \text { TSB } & \text { Trypticase soy broth } \\ \text { W } & \text { Width } \\ \mu l & \text { Microliter }\end{array}$

\section{Introduction}

Infections of the spinal column such as spontaneous osteomyelitis or post-surgical infections are rare but increasing pathologies due to the ageing population and increasing numbers of comorbidities with mortality rates up to $17 \%$ [1-3]. Mild infections can be treated conservatively whereas patients with sepsis, osseous destruction and/or neurological deficits due to compression of the spinal cord or the nerve roots need decompressive surgery and/or stabilisation. Resection of the affected intervertebral disc(s) and stabilisation with intervertebral fusion is recommended in these cases. The gold-standard is still the implantation of a dorsal titanium screws-rod-system with either a titanium intervertebral cage or a cortical bone autograft [4, 5], although lately studies had shown that cages made of polyetheretherketon (PEEK) can be a safe and feasible alternative implant material in patients with osteomyelitis [6-8].

The most common causative bacterial species for spondylodiscitis or osteomyelitis are S.aureus with an incidence between 30 and $80 \%$, S.epidermidis with rates up to over $10 \%$ and MRSA $(6.1 \%)$. Gram-negative bacteria are responsible for up to $25 \%$ of spinal infections, with E.coli being reported as the most common (5.6\%) [9-11].

Even if there are many studies on osteomyelitis, there is still no final guideline for the correct treatment and choice of implant materials $[12,13]$. Autologous bone grafts and titanium implants have been shown to have reduced bacterial adhesion characteristics, whereas PEEK cages are radiolucent, allow better follow-up diagnostics with computed tomography (CT) and magnetic resonance imaging (MRI) due to less artefacts and are advantageous according to better load sharing at dissolved endplates in osteomyelitis $[14,15]$. Clinical studies concentrate on bacterial counts on explanted stabilisation material of post-surgical infections or re-infection rates after the use of PEEK cages [6, 8]. Experimental studies evaluated the influence of topography and chemistry on bacterial adhesion on different biomaterials [14, 15]. However, to our knowledge, this in vitro study is the first to actually quantitatively evaluate differences in biofilm formation on two intervertebral cages made of PEEK and titanium, which are in clinical use.

\section{Methods}

\section{Biomaterials}

For baseline experiments round plates (diameter: $12 \mathrm{~mm}$, height: $2 \mathrm{~mm}$ ) made from PEEK, smoothly polished titanium (Ti), and titanium with 2 surfaces, one side roughly polished and the other with a porous trabecular structure (TiMe) were provided by a medical device company (Spineart, Plan-les-Ouates, Switzerland)(Fig. 1a). Additionally, original interbody oblique cages made of PEEK (L32 mm, H12 mm; Spineart, Plan-les-Ouates, Switzerland) and 3D printed titanium cages with a porous trabecular structured centre (TiLi; L32 mm, H12 mm, W10.5 mm, $6^{\circ}$ angle; Spineart, Plan-les-Ouates, Switzerland) were used (Fig. 1b). Titanium and PEEK plates were machine produced followed by a bead-blasting process to remove burrs. The TiMe plates, however, were $3 \mathrm{D}$ printed in one piece, the same way as the manufacturing process of the TiLi cages, without any post-treatment. Only the contour of the TiLi cages is polished, the trabecular structure remaining intact. All samples were supplied sterilised as the standard cages for human implantation.

\section{Microorganisms and growth conditions}

Bacteria strains were thawed from a glycerol cryo stock and plated over night at $37{ }^{\circ} \mathrm{C}$ on trypticase soy broth (TSB) agar plates or lysogeny broth (LB) agar plates, respectively. For inoculation of biomaterials single colonies of methicillin-susceptible and methicillin-resistant S.aureus (MSSA: ATCC 25,923, MRSA: ATCC 43,300), and S.epidermidis (ATCC 12,228) strains were cultured in $2 \mathrm{ml}$ TSB and incubated over night at $37^{\circ} \mathrm{C}$ with $200 \mathrm{rpm}$ shaking. Gram-negative E.coli (ATCC 25,922) was grown in LB.

In order to assess bacterial survival in phosphate-buffered saline (PBS), bacterial overnight cultures were diluted 1:200 in PBS, and $200 \mu \mathrm{l}$ placed in a microtiter plate. Growth was monitored after $0,8,24,28,32,48,52,56,72,76$ and $80 \mathrm{~h}$ 
Fig. 1 Tested materials and structures. a Manufactured material samples sized $12 \mathrm{~mm}$ in diameter and 2-mm-height and PEEK as well as 3D-printed titanium cages with a trabecular mesh centre which are in clinical use for intercorporal implantation in spinal stabilisation procedures. From left to right: Plates made of PEEK, polished titanium and titanium mesh (TiMe) with 2 sides, roughly polished titanium and trabecular mesh. b Original interbody oblique cages, length-32-mm and height-12-mm, made of PEEK (left) and 3D-printed titanium with a porous trabecular structured centre (Spineart, Plan-les-Ouates, Switzerland) a
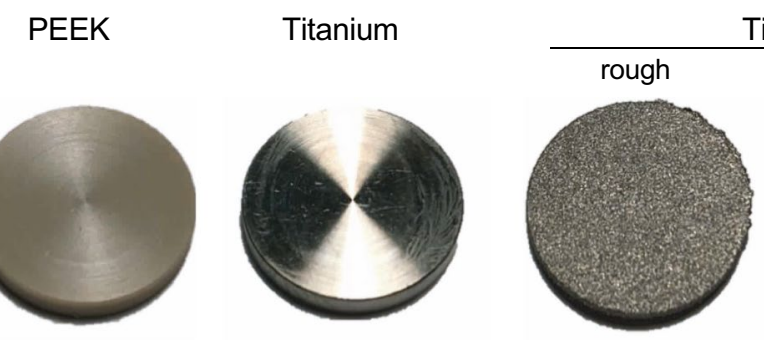

TiMe

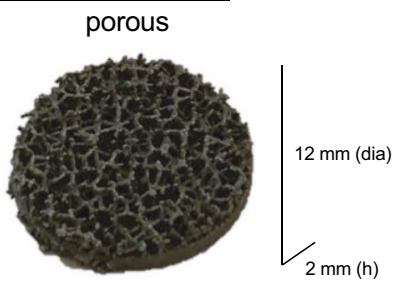

b
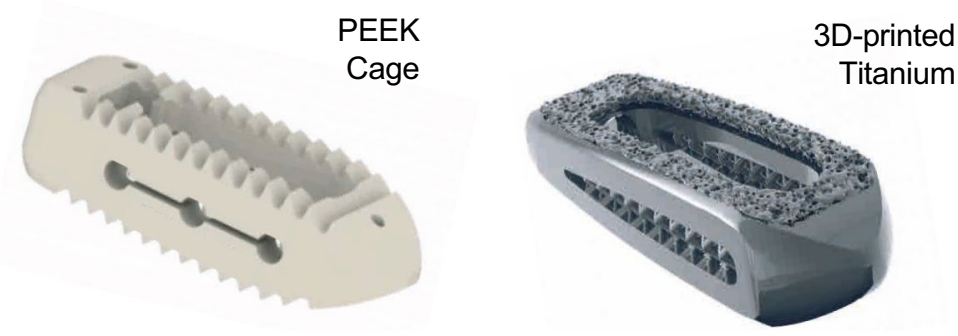

in a microplate reader measuring the optical density $\mathrm{OD}_{600}$ (Tecan, Männedorf, Switzerland).

\section{Quantification of bacterial adherence}

Bacteria from an overnight culture were diluted by measuring the $\mathrm{OD}_{600}$, and stock solutions containing $10^{5} \mathrm{CFU}$ were prepared in PBS. The three different biomaterials were inoculated in bacterial stock solutions for 8, 24, 32, 48, 56, 72 and 80 h, and the cages for 8 and 72 h, respectively. For each time point, sample and bacteria control was incubated only in PBS. Afterwards biomaterials were rinsed with PBS, covered with $2 \mathrm{ml}$ PBS, and surface adherent bacteria were removed into solution by 3 min $100 \%$ ultrasound in an ultrasound bath (Bandelin BactoSonic, Berlin, Germany). Serial dilutions of bacteria suspensions were plated in at least duplicates on Mueller-Hinton agar plates, and growth was monitored after $24 \mathrm{~h}$ by counting CFU macroscopically.

\section{Confocal laser scanning microscopy analysis}

Biofilms were formed in vitro in $\mu$-Angiogenese slides (ibidi, Martinsried/Planegg, Germany) and at appropriate time points fixed in $3.7 \%$ paraformaldehyde and stained with 4',6-Diamidine-2'-phenylindole dihydrochloride (DAPI) nucleic acid stain (Sigma-Aldrich, MO, USA) for visualisation of cells. Stained biofilms were visualised under a TCS SP8 X confocal laser scanning microscope (Leica, Wetzlar, Germany). Biofilms were observed using a $63 \times$ oil-immersion objective, and images of different regions of each surface were acquired with $1024 \times 1024$ resolution. Two independent biological experiments of in vitro biofilm formation of the different strains were performed, and representative images were selected. Images were reconstructed from average intensity projection through confocal image Z-stacks series using ImageJ [16].

\section{Electron microscopy analysis}

Scanning electron microscopy (SEM) was performed to localise MSSA, MRSA, S.epidermidis and E.coli on the cage surfaces. The cages were inoculated with bacterial stock solution $\left(10^{5} \mathrm{CFU}\right)$, incubated for $72 \mathrm{~h}$, fixed in $4 \%$ paraformaldehyde, and PEEK cages were additionally sputter coated with carbon to enable conductive behaviour and prevent static electricity. High-resolution images of the cage surfaces were generated with a secondary electron detector attached to a Crossbeam 340 (Carl Zeiss Microscope GmbH, Jena, Germany) system, which was operated at an electron beam voltage of $5 \mathrm{kV}$ and a working distance of $5 \mathrm{~mm}$. Three different observers (TK, SW and SvK) evaluated the electron microscopic images and chose representative sections.

\section{Statistics}

Statistical testing was performed using Graphpad Prism 8. A Shapiro-Wilk and D'Agostino-Pearson omnibus normality test was performed, and Kruskal-Wallis test was used for statistical analysis and data comparison. Results were deemed significant at $p<0.05$. 


\section{Results}

\section{Quantification of bacterial adherence to implant materials}

Plates: Two plates of each material were inoculated for time points $24,32,48,56,80 \mathrm{~h}(n=10)$, three plates for time points 8 and $72 \mathrm{~h}(n=6)$ and each bacterial species (in total 192 samples). The solution of surface adherent bacteria for each plate was transferred to three agar plates (in total 576 agar plates). A moderate or sharp increase in cell attachment of the bacterial solutions could be detected for MSSA, MRSA and E.coli after 72 or 80 h, respectively. For S.epidermidis only a mild increase of adherence on titanium (Ti) could be detected (Supplemental Fig. S1a and Fig. 2a). Overall, bacterial load of the Ti incubated solution was lower after 72 and $80 \mathrm{~h}$ compared to PEEK and TiMe. Detailed bacterial counts in mean CFU with standard deviation (SD) are shown in supplemental Fig. S1a for all plate materials. Comparable to the following results of the cages, the results of cell attachment of the bacterial solution of PEEK vs. TiMe plates are of particular interest. The only significant difference in those two materials was at $32 \mathrm{~h}$ for MSSA with significantly less bacterial adherence on TiMe plates compared to PEEK plates $(p=0.02)$. No significant difference could be found for the other time points or for MRSA, S.epidermidis and E.coli (Fig. 2b).

Cages: PEEK cages and TiLi cages were inoculated for 8 and $72 \mathrm{~h}$, respectively (4 cages each), with all three grampositive bacteria and E.coli (in total 64 cages). The bacterial solution of each cage was then transferred to three agar plates (in total 192 agar plates) (Fig. 3a and Supplemental Fig. S1b). No significant difference could be detected after $8 \mathrm{~h}$ for MSSA, MRSA and E.coli. S.epidermidis showed a significantly lower amount of CFU at both time points with $p=0.02$ and $p=0.008$ after inoculation of the isolated solution of the bacterial adherence on the TiLi cage (Fig. 3). After $72 \mathrm{~h}$, a significant difference with less bacterial attachment for MSSA and S.epidermidis could be detected for the TiLi cages with $p=0.002$ and $p=0.008$, respectively. The gram-negative E.coli species showed a different behaviour with a significantly higher CFU for the TiLi cages after $72 \mathrm{~h}$ $(p=0.05)$. No significant difference could be detected at both time points for MRSA (Fig. 3b).

All controls showed no bacterial growth after the respective time points of inoculation in PBS only.

\section{Confocal laser scanning microscopy analysis}

When analysing biofilm formation in an in vitro assay different types of multicellular layers can be observed
(Fig. 4). After $8 \mathrm{~h}$ of growth Staphylococci accumulate in small cell clusters forming a dense and thick biofilm after 80 h. As depicted in Fig. 4 in the XZ view for lateral presentation these bacteria form a compact cell mass with no space in between. The rod-shaped E.coli on the other hand show an even cell distribution without clustering after 8 and $80 \mathrm{~h}$ of growth.

\section{Electron microscopy analysis}

Representative images of the plates and cage surfaces generated by SEM are shown in Fig. 5. No bacteria were found at the porous structured side of the plates or in the trabecular mesh centre of the titanium cages (Fig. 5a "TiMe mesh" and Fig. 5c). Smoothly polished titanium plates also revealed small grooves of the manufacturing process where bacteria could adhere, but less than on the PEEK plates or cages with a more inhomogeneous surface (Fig. 5a). In both, PEEK and TiLi cages all bacteria were only adhering at the border zones of different surface structures. In detail, they were localised in the transition area from polished titanium to the mesh centre in the TiLi cage. The transition zone is illustrated in Fig. 5c. Bacteria were located on the polished part of the titanium cage which is shown in the right panel of Fig. $5 b$ representing an image section of Fig. 5c. On PEEK cages bacteria were adhering primarily on the transition area from smooth to serrated parts.

\section{Discussion}

Our study evaluates and compares PEEK and 3D printed trabecular metal (titanium) cages according to their bacterial adhesion characteristics aiming to gain recommendations for the use in cases of osteomyelitis or spondylodiscitis where there is still no final guideline what kind of material for intercorporal cages is best to prevent re-infections and also guarantee bony fusion [17]. Both is provided by autologous bone from the iliac crest, but as it is still associated with a high risk of donor site morbidity and complications cages are more often used in recent years [11]. As there are numerous cages for spinal implantation on the market which vary in their materials and surfaces, we decided to compare a rather new 3D-printed titanium cage with a common PEEK cage. For better comparability of the size and surface design we used special manufactured plates of the same materials in the first stage of the study to assess the differences in bacterial adhesion characteristics. We focused on the comparison between PEEK and titanium cages with a trabecular surface and centre as it was suspicious that bacteria would adhere especially at parts with larger surface $[18,19]$.

Bacteria were chosen according to their frequency, reported in literature as well as the incidence of the patient 
a

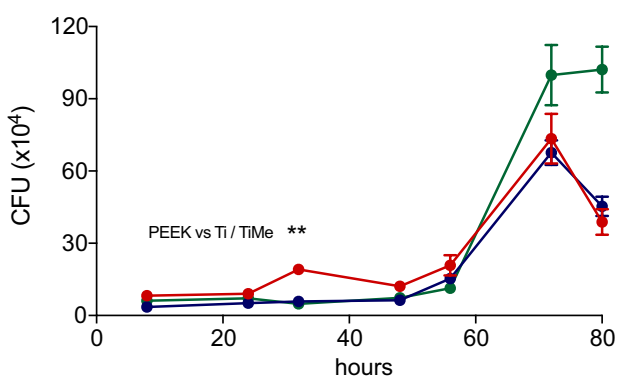

S. epidermidis

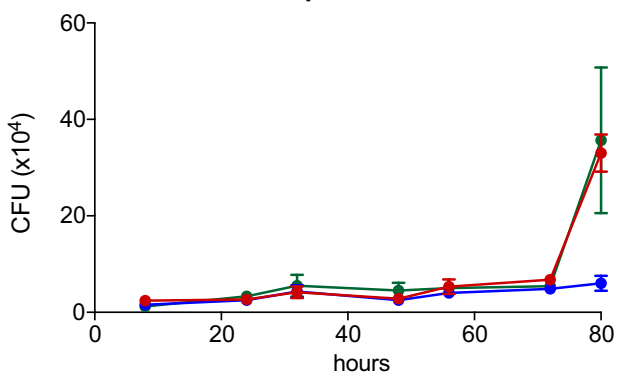

MRSA

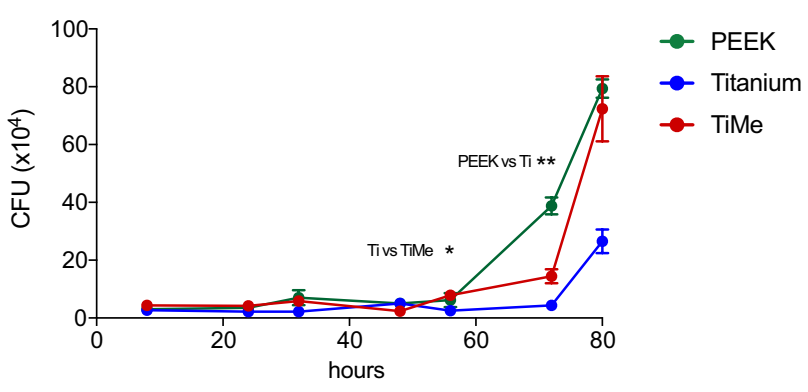

E. coli

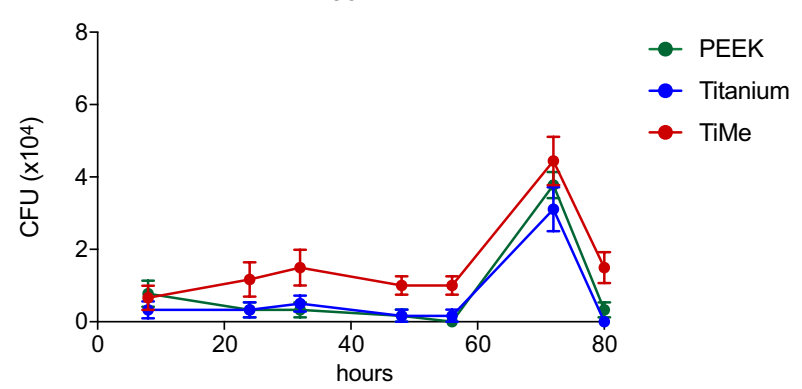

b

\begin{tabular}{|c|c|c|c|c|c|c|c|}
\hline \multirow{2}{*}{ W } & \multicolumn{7}{|c|}{ IVISSA } \\
\hline & $8 \mathrm{~h}$ & $24 \mathrm{~h}$ & $32 \mathrm{~h}$ & $48 \mathrm{~h}$ & $56 \mathrm{~h}$ & $72 \mathrm{~h}$ & $80 \mathrm{~h}$ \\
\hline PEEK vs. Ti & 0.29 & 0.58 & 0.68 & 0.91 & 0.81 & 0.87 & 0.69 \\
\hline PEEK vs. TiMe & 0.5 & 0.83 & 0.02 & 0.32 & 0.78 & 0.86 & 0.63 \\
\hline Ti vs. TiMe & 0.08 & 0.44 & 0.07 & 0.27 & 0.98 & $>0.99$ & 0.93 \\
\hline
\end{tabular}

MRSA

\begin{tabular}{|c|c|c|c|c|c|c|c|}
\hline & $8 h$ & $24 \mathrm{~h}$ & $32 \mathrm{~h}$ & $48 \mathrm{~h}$ & $56 \mathrm{~h}$ & $72 \mathrm{~h}$ & $80 \mathrm{~h}$ \\
\hline PEEK vs. Ti & $>0.99$ & 0.44 & 0.29 & 0.96 & 0.36 & 0.005 & 0.59 \\
\hline PEEK vs. TiMe & 0.41 & 0.92 & 0.67 & 0.42 & 0.27 & 0.26 & 0.96 \\
\hline Tivs. TiMe & 0.46 & 0.39 & 0.13 & 0.44 & 0.04 & 0.09 & 0.63 \\
\hline
\end{tabular}

\section{S. epidermidis}

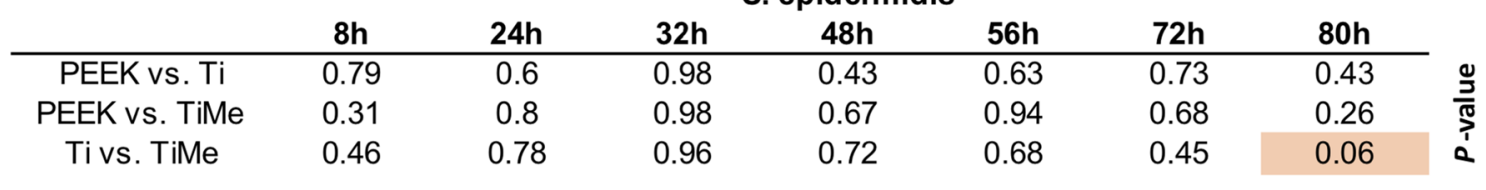

\begin{tabular}{|c|c|c|c|c|c|c|c|}
\hline & \multicolumn{7}{|c|}{ E. coli } \\
\hline & $8 \mathrm{~h}$ & $24 \mathrm{~h}$ & $32 \mathrm{~h}$ & $48 h$ & $56 \mathrm{~h}$ & $72 \mathrm{~h}$ & $80 \mathrm{~h}$ \\
\hline PEEK vs. Ti & 0.67 & $>0.99$ & 0.88 & $>0.99$ & 0.88 & 0.58 & 0.76 \\
\hline PEEK vs. TiMe & 0.91 & 0.51 & 0.36 & 0.45 & 0.37 & 0.85 & 0.34 \\
\hline Ti vs. TiMe & 0.75 & 0.51 & 0.45 & 0.45 & 0.45 & 0.46 & 0.21 \\
\hline
\end{tabular}

Fig. 2 In vitro incubation and growth comparison of different bacterial strains on diverse materials (plates). a Representative growth curves of the in vitro inoculation (mean and standard deviation (SD) in colony forming units (CFU)). Statistical significant differences between the materials are indicated in the respective graphs as $*=p<0.05$ and $* *=p<0.01$. b Statistical comparison of individual growth curves and analysis of growth characteristics between differ- ent materials (one-way ANOVA and Kruskal-Wallis test). The significant results are marked bold and coloured according to their significance. Red colouring indicates advantage (less bacteria) of Ti versus $\mathrm{TiMe}$, while green colouring indicates advantage of $\mathrm{Ti}$ or TiMe over PEEK. $n=2,3$ cultures each for time points $24,32,48,56$ and $80 \mathrm{~h}$ (h); $n=3,3$ cultures each for 8 and $72 \mathrm{~h}$ 

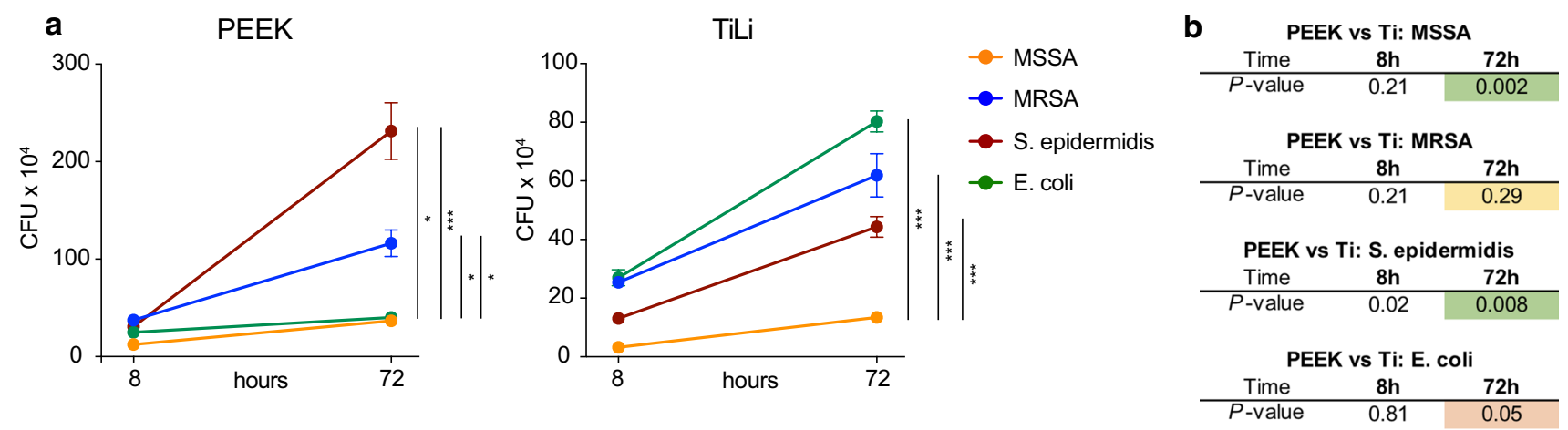

Fig. 3 In vitro incubation and growth comparison of different bacterial strains on diverse materials (cages). a Growth curve comparison with individual values in CFU $\times 10^{4}$ after 8 and $72 \mathrm{~h}$ for PEEK and 3D-printed titanium oblique cages. Statistical significant differences between the bacteria are indicated in the respective graphs as $*=p<0.05, \quad * *=p<0.01$ and $* * *=p<0.001$. b Statistical analysis with comparison of bacterial adhesion of MSSA, MRSA, S.epidermidis and E.coli on PEEK and titanium cages (Ti). One-way ANOVA and Kruskal-Wallis test reveal an advantage (less bacteria) of titanium over PEEK (green colouring) whereas red colouring indicates advantage of PEEK over titanium. Yellow colouring depicts not significant values. $n=4,3$ cultures each
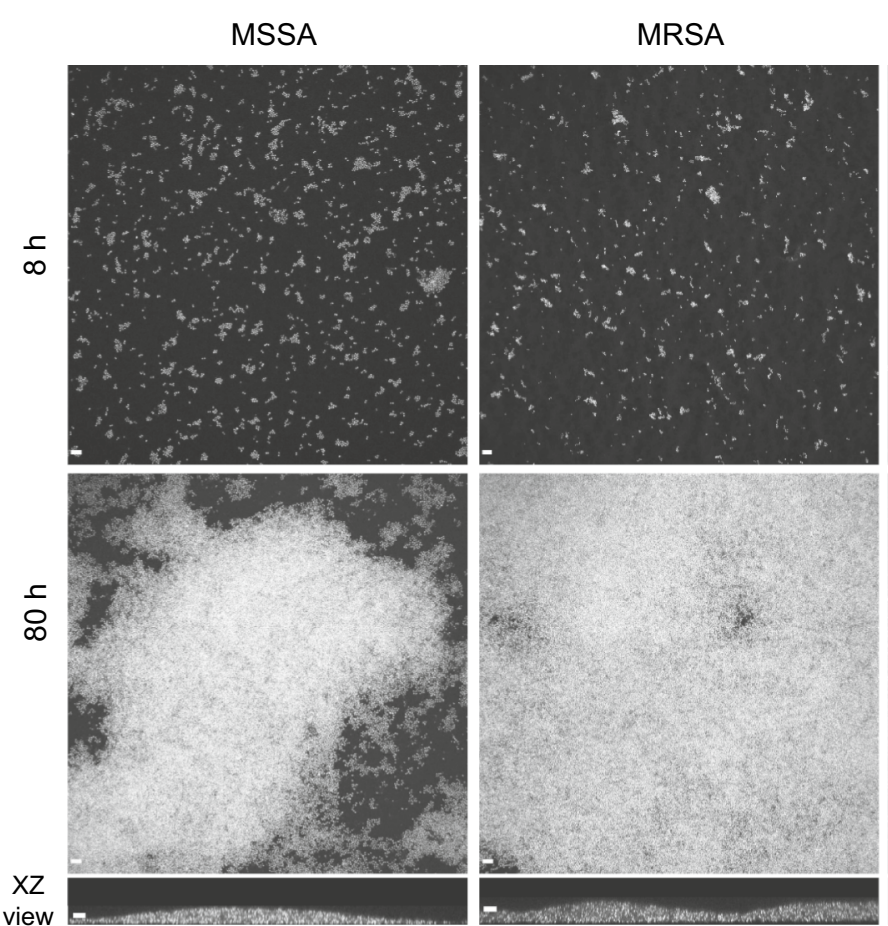

S. epidermidis
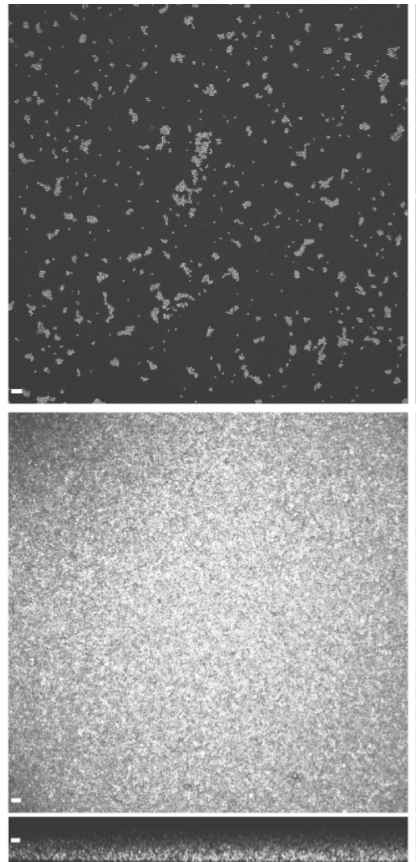

E. coli
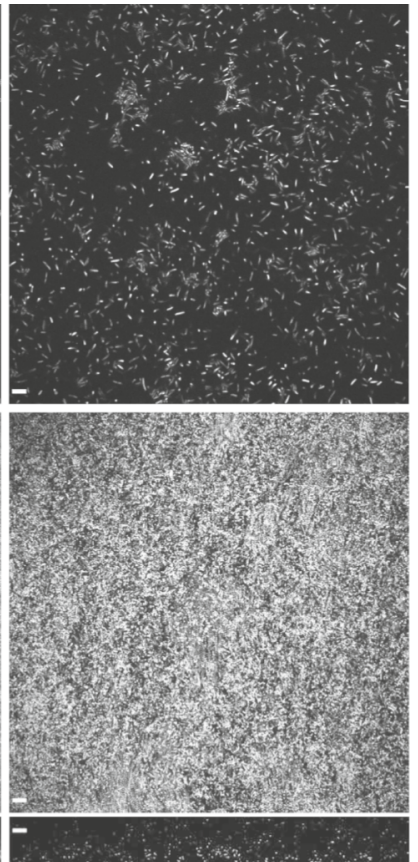

Fig. 4 Confocal laser scanning microscopy analysis of in vitro biofilm formation of the different bacterial strains. Bacteria were stained with DAPI nucleic acid stain (white). From left to right biofilm formation of the different bacteria MSSA, MRSA, S.epidermidis and E.coli after 8 and $80 \mathrm{~h}$ is shown. For better comparison of the biofilm

cohort in our institution, in causing either spontaneous spondylodiscitis or osteomyelitis and post-surgical infections of the spine. MSSA was chosen as one of the gram-positive bacteria as it is the most common bacteria causing spontaneous spondylodiscitis with an incidence up to $80 \%$ and is also predominant in iatrogenic spondylodiscitis. S.epidermidis structure, a XZ view was generated (lower panel). MSSA, MRSA and S.epidermidis form dense cellular structures whereas E.coli displays growth in multicellular layers. Bars MSSA, MRSA and S.epidermidis: $5 \mu \mathrm{m}$. Bar E.coli: $10 \mu \mathrm{m}$

and MRSA are representatives for perioperative contamination and a multiresistant hospital germ. E.coli was chosen as it is the most often detected gram-negative bacteria which is mainly located in the lower intestine from where especially postoperatively a smear infection of the wound can occur $[10,11,20-22]$. 
a

Plates (material comparison)
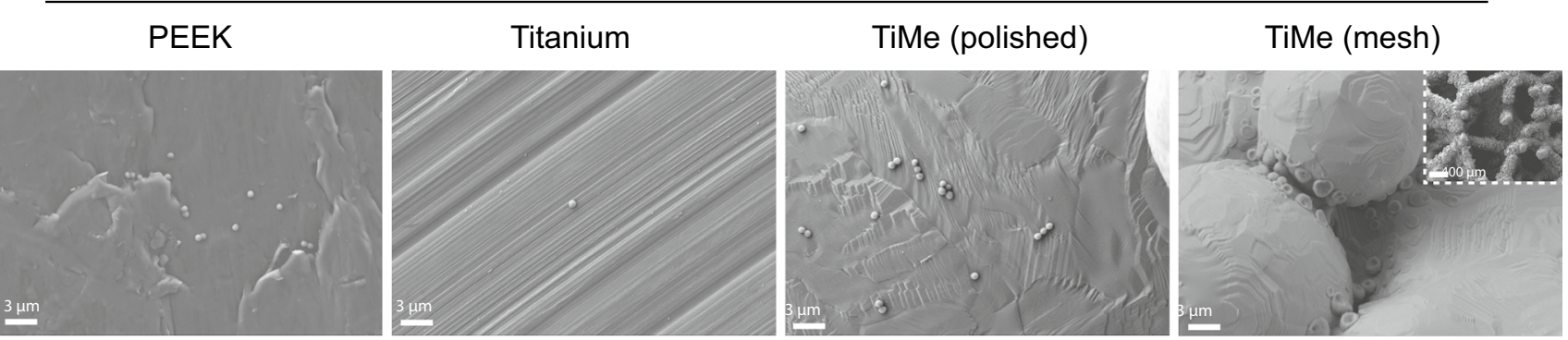

b
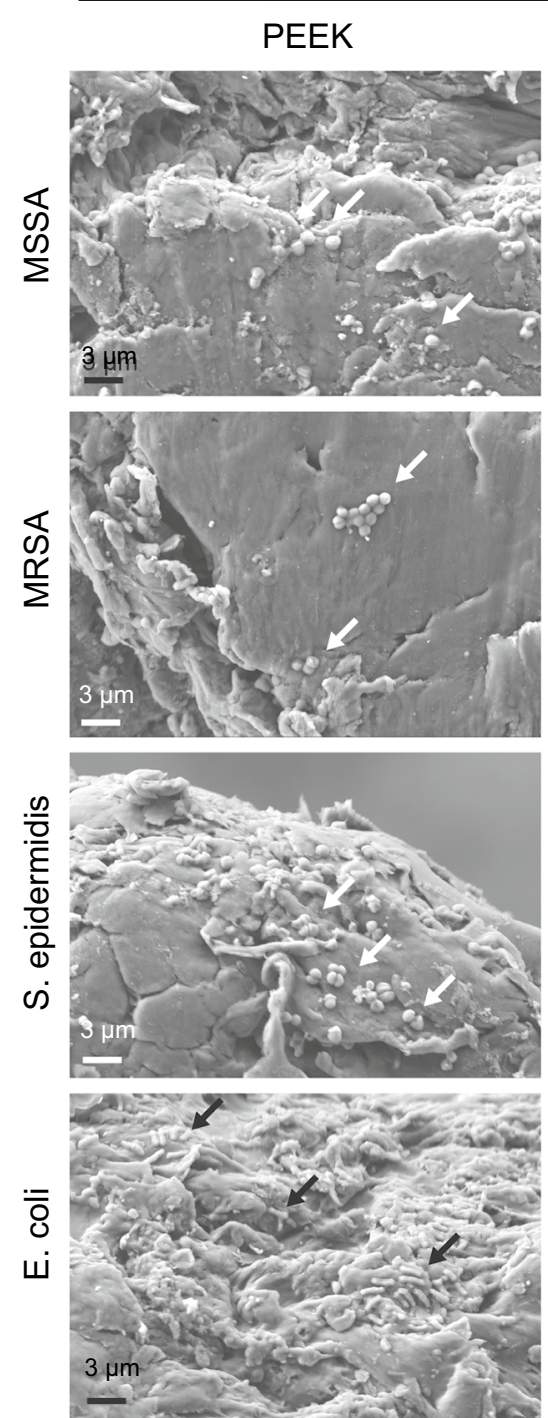

Cages

TiLi
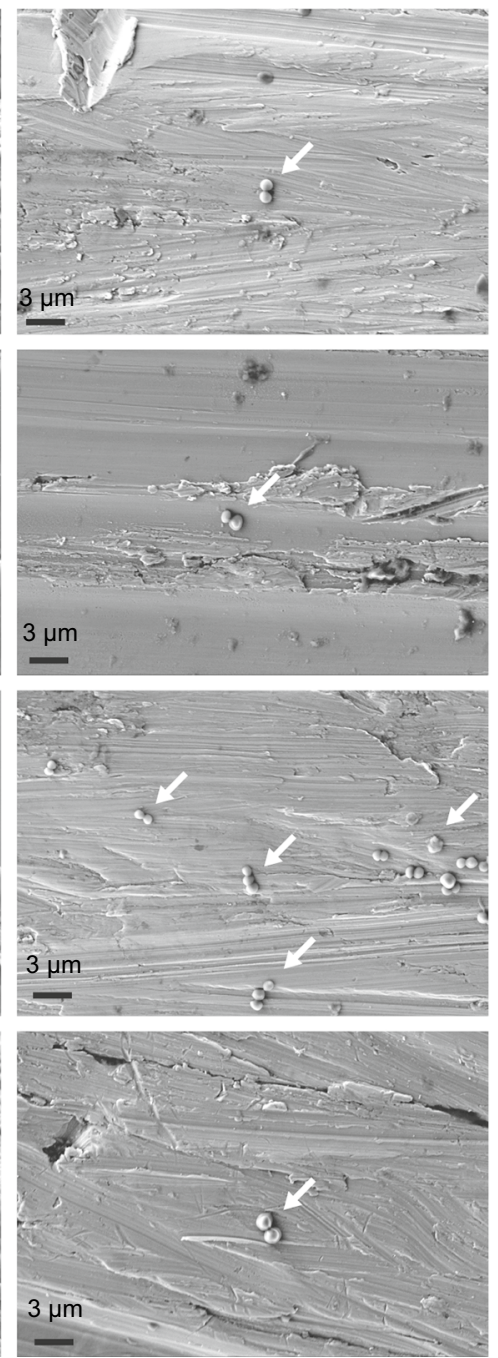

c

TiLi: surface transition zone

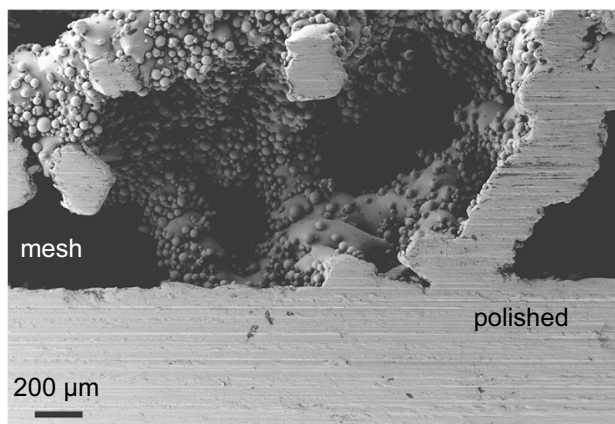

$200 \mu \mathrm{m}$
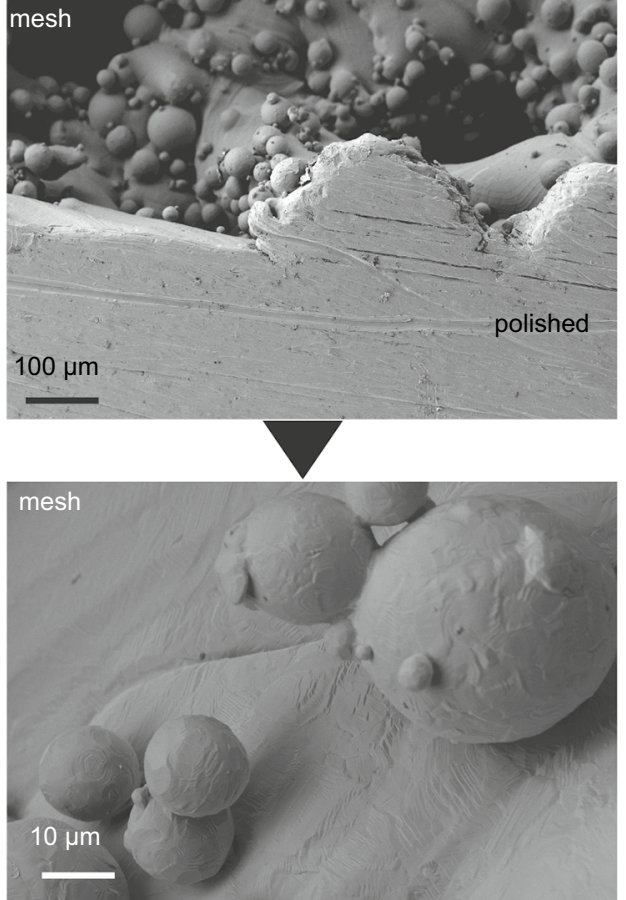

Fig. 5 Electron microscopy analysis with representative images of the different plate materials and parts of the cages with maximum bacterial adhesion. a Shows the different manufactured materials PEEK, polished titanium and titanium mesh (TiMe) with the 2 sides of roughly polished titanium and the mesh centre structure. Bars: $3 \mu \mathrm{m}$. The right image of TiMe (mesh) has an additional image in the right upper corner which displays a window of a greater overview of the mesh structure with $b a r=400 \mu \mathrm{m}$. The first three images also show adherent Staphylococci. b PEEK (left panel) and 3D-printed titanium cages (right panel) show adherent bacteria (white arrows) of MSSA, MRSA, S.epidermidis and E.coli. Bars $=3 \mu \mathrm{m}$. Image sections are taken of transition zones between smoother and serrated parts of the PEEK cages and of the polished part next to the trabecular centre of the titanium cages (see Fig. 5c). c Transition zone of the 3D-printed titanium cage in different magnifications 
In our study, an overall increase of bacterial growth could be detected at $72 \mathrm{~h}$, which is $24-48 \mathrm{~h}$ later than shown by Bal and Gorth et al. who used titanium, PEEK and silicon nitride inoculated with S.aureus, S.epidermidis, Pseudomonas aeruginosa, E.coli and Enterococcus in a similar setting [15]. Due to the high cost of the original cages, we chose representative inoculation times of 8 and $72 \mathrm{~h}$ as an increase of bacterial adherence on the plates could be shown after $72 \mathrm{~h}$ for most bacteria strains. The quantitative analysis showed significantly higher CFU counts on PEEK compared to TiLi cages for MSSA and S.epidermidis after $72 \mathrm{~h}$, for S.epidermidis also after $8 \mathrm{~h}$. Potential reasons might be the rougher machined PEEK surface which provides a better anchorage for the bacteria with micron scale crevices, overlaps and ridges which was previously shown in literature [14, 23, 24]. Against our expectations, SEM images showed no bacteria in the titanium mesh structure cages, which harbour the overall largest surface of the plates or cages. This might be owed to the blast finishing process making the surface features of the titanium mesh more rounded as opposed to the rather sharp edges of the PEEK finish. Both findings are in line with the study of Rochford et al. who also showed a significantly higher number of bacteria on rougher machined PEEK samples with more crevices and folds compared to injection moulded PEEK with a relatively smooth surface and their titanium samples [14]. It is also known that bacterial adhesion is favoured on recessed portions of micro patterned surfaces, and adhesion is greatly impaired when patterning is smaller than the size of the bacteria [25]. Micro-and nanoscale patterning on even the blast finishing of the trabecular structured centre of the titanium cages is still smaller than the irregularities of the PEEK surface which can also be a reason for favoured bacterial adhesion on PEEK rather than the trabecular centre of the titanium cages. SEM also revealed that only the border zones from smoothly polished parts to the mesh structure of the titanium cages seemed suitable for bacterial attachment. Rochford et al. demonstrated similar findings with adherence of bacteria on modified PEEK surfaces on the plateaus between pits, but not in the pits [14].

For colonisation of E.coli on the cages, quantitative analysis and SEM imaging revealed diverse results with a significantly higher count of CFU on TiLi cages than on the PEEK cages after $72 \mathrm{~h}$, but many typically rod-shaped E.coli bacteria on the PEEK cages on SEM. Usually, microorganisms attach more likely to hydrophobic and non-polar surfaces like plastic than to hydrophilic and polar surfaces like metal [26]. Several gram-negative bacteria have, however, other than gram-positive, flagella and pili which help to adhere on rougher surfaces of implant devices [21, 25, 26]. The titanium cages have a smoother surface on the polished parts, but the surface of the trabecular centre might improve the adhesion of gram-negative bacteria. The trabecular centre is also a striking difference to the titanium, smoothly machined, which is used by Bal et al. where they did not find any difference of E.coli adhesion on titanium or PEEK [15]. E.coli can also form long polysaccharide chains being involved in the interaction with material surfaces at the initial adhesion which is a distinct difference between Staphylococci and E.coli and can possibly be responsible for the higher CFU on titanium cages for E.coli compared to PEEK in our study [25].

A major limitation of our study is the low number of diluted samples. However, although significant statistical results could be obtained, further studies with larger numbers might consolidate our results which show that the newer titanium cages are not inferior to and might be even advantageous over PEEK in osteomyelitis due to their individual bacterial adhesion characteristics. As Rochford et al. have shown the ability of coagulase positive S.aureus to cause clotting of blood plasma, which itself can cause bacterial adhesion [14], a study protocol with and without the influence of human blood proteins could be interesting as well and interactions of bacteria with biomaterial surfaces are of course more complex in vivo than in vitro models can simulate [22].

Overall, our study could confirm a non-inferiority of titanium cages even with a trabecular structure compared to PEEK cages according to bacterial adherence. We could show that titanium might be advantageous, at least in grampositive bacteria.

For clinical practice, our findings imply that despite the enlarged surface of the 3D-printed titanium cage Staphylococci adhere less than on PEEK cages, and therefore, it should be taken into consideration to give the advantage in infectious processes when stabilisation of the spine is needed. For cases, where E.coli is isolated or suspected, it might be better to use PEEK instead of titanium cages. In the future, additional studies are needed to further elucidate potential in vivo factors affecting the adhesion characteristics on different implant materials.

Acknowledgments We thank Spineart, Switzerland, for providing the samples and cages for this study and Tim Rolvien, MD, Department of Osteology and Biomechanics and Department of Orthopaedics, University Medical Centre Hamburg-Eppendorf, Hamburg, Germany, for establishing contact to SvK.

Funding Open Access funding enabled and organized by Projekt DEAL..

\section{Compliance with ethical standards}

Conflict of interest The authors have any potential conflict of interest.

Open Access This article is licensed under a Creative Commons Attribution 4.0 International License, which permits use, sharing, adaptation, distribution and reproduction in any medium or format, as long 
as you give appropriate credit to the original author(s) and the source, provide a link to the Creative Commons licence, and indicate if changes were made. The images or other third party material in this article are included in the article's Creative Commons licence, unless indicated otherwise in a credit line to the material. If material is not included in the article's Creative Commons licence and your intended use is not permitted by statutory regulation or exceeds the permitted use, you will need to obtain permission directly from the copyright holder. To view a copy of this licence, visit http://creativecommons.org/licenses/by/4.0/.

\section{References}

1. Kehrer M, Pedersen C, Jensen TG, Lassen AT (2014) Increasing incidence of pyogenic spondylodiscitis: a 14-year population-based study. J Infect 68:313-320. https://doi.org/10.1016/j. jinf.2013.11.011

2. Murillo O, Grau I, Lora-Tamayo J et al.(2015) The changing epidemiology of bacteraemic osteoarticular infections in the early 21st century. Clin Microbiol Infect 21:254.e1-254.e8. https://doi. org/10.1016/j.cmi.2014.09.007

3. Kurtz SM, Lau E, Ong KL et al.(2012) Infection risk for primary and revision instrumented lumbar spine fusion in the Medicare population. J Neurosurg Spine 17:342-347. https://doi. org/10.3171/2012.7.SPINE12203

4. Ruf M, Stoltze D, Merk HR et al.(2007) Treatment of vertebral osteomyelitis by radical debridement and stabilization using titanium mesh cages. Spine 32:275-280. https://doi.org/10.1097/01. brs.0000261034.83395.7f

5. Robinson Y, Tschoeke SK, Finke T et al.(2008) Successful treatment of spondylodiscitis using titanium cages: a 3-year follow-up of 22 consecutive patients. Acta Orthop 79:660-664. https://doi. org/10.1080/17453670810016687

6. Schomacher M, Finger T, Koeppen D et al.(2014) Application of titanium and polyetheretherketone cages in the treatment of pyogenic spondylodiscitis. Clin Neurol Neurosurg 127:65-70. https ://doi.org/10.1016/j.clineuro.2014.09.027

7. Tschöke SK, Fuchs H, Schmidt O et al.(2015) Single-stage debridement and spinal fusion using PEEK cages through a posterior approach for eradication of lumbar pyogenic spondylodiscitis: a safe treatment strategy for a detrimental condition. Patient Saf Surg 9:35. https://doi.org/10.1186/s13037-015-0083-4

8. Shiban E, Janssen I, da Cunha PR et al.(2016) Safety and efficacy of polyetheretherketone (PEEK) cages in combination with posterior pedicel screw fixation in pyogenic spinal infection. Acta Neurochir (Wien) 158:1851-1857. https://doi.org/10.1007/s0070 1-016-2924-z

9. Nolla JM, Ariza J, Gómez-Vaquero C et al.(2002) Spontaneous pyogenic vertebral osteomyelitis in nondrug users. Semin Arthritis Rheum 31:271-278. https://doi.org/10.1053/sarh.2002.29492

10. Sobottke R, Seifert H, Fätkenheuer G et al.(2008) Current diagnosis and treatment of spondylodiscitis. Dtsch Aerzteblatt Online. https://doi.org/10.3238/arztebl.2008.0181

11. Korovessis P, Vardakastanis K, Fennema P, Syrimbeis V (2016) Mesh cage for treatment of hematogenous spondylitis and spondylodiskitis. How safe and successful is its use in acute and chronic complicated cases? a systematic review of literature over a decade. Eur J Orthop Surg Traumatol 26:753-761. https://doi. org/10.1007/s00590-016-1803-x
12. Berbari EF, Kanj SS, Kowalski TJ et al.(2015) 2015 Infectious diseases society of america (IDSA) clinical practice guidelines for the diagnosis and treatment of native vertebral osteomyelitis in adults. Clin Infect Dis 61:e26-e46. https://doi.org/10.1093/cid/ civ482

13. Stüer C, Stoffel M, Hecker J et al.(2013) A staged treatment algorithm for spinal infections. J Neurol Surg Part A Cent Eur Neurosurg 74:087-095. https://doi.org/10.1055/s-0032-1320022

14. Rochford ETJ, Poulsson AHC, Salavarrieta Varela J et al.(2014) Bacterial adhesion to orthopaedic implant materials and a novel oxygen plasma modified PEEK surface. Coll Surf B Biointerfaces 113:213-222. https://doi.org/10.1016/j.colsurfb.2013.09.012

15. Bal S, Gorth D, Puckett S et al.(2012) Decreased bacteria activity on Si3N4 surfaces compared with PEEK or titanium. Int J Nanomed 7:4829-4840. https://doi.org/10.2147/IJN.S35190

16. Rueden CT, Schindelin J, Hiner MC et al.(2017) Image J2: imageJ for the next generation of scientific image data. BMC Bioinformatics. https://doi.org/10.1186/s12859-017-1934-Z

17. Grados F, Lescure FX, Senneville E et al.(2007) Suggestions for managing pyogenic (non-tuberculous) discitis in adults. Jt bone spine 74:133-139. https://doi.org/10.1016/j.jbspin.2006.11.002

18. Ren Y, Wang C, Chen $Z$ et al.(2018) Emergent heterogeneous microenvironments in biofilms: substratum surface heterogeneity and bacterial adhesion force-sensing. FEMS Microbiol Rev 42:259-272. https://doi.org/10.1093/femsre/fuy001

19. Palmer J, Flint S, Brooks J (2007) Bacterial cell attachment, the beginning of a biofilm. J Ind Microbiol Biotechnol 34:577-588. https://doi.org/10.1007/s10295-007-0234-4

20. Duarte RM, Vaccaro AR (2013) Spinal infection: state of the art and management algorithm. Eur Spine J 22:2787-2799. https:// doi.org/10.1007/s00586-013-2850-1

21. Costerton JW, Stewart PS, Greenberg EP (1999) Bacterial biofilms: a common cause of persistent infections. Science 284:1318 1322. https://doi.org/10.1126/science.284.5418.1318

22. Arciola CR, Campoccia D, Montanaro L (2018) Implant infections: adhesion, biofilm formation and immune evasion. Nat Rev Microbiol 16:397-409. https://doi.org/10.1038/s4157 9-018-0019-y

23. Harris LG, Meredith DO, Eschbach L, Richards RG (2007) Staphylococcus aureus adhesion to standard micro-rough and electropolished implant materials. J Mater Sci Mater Med 18:1151-1156. https://doi.org/10.1007/s10856-007-0143-0

24. Wu Y, Zitelli JP, TenHuisen KS et al.(2011) Differential response of Staphylococci and osteoblasts to varying titanium surface roughness. Biomaterials 32:951-960. https://doi.org/10.1016/j. biomaterials.2010.10.001

25. Berne C, Ellison CK, Ducret A, Brun YV (2018) Bacterial adhesion at the single-cell level. Nat Rev Microbiol 16:616-627. https ://doi.org/10.1038/s41579-018-0057-5

26. Jamal M, Ahmad W, Andleeb S et al.(2018) Bacterial biofilm and associated infections. J Chin Med Assoc 81:7-11. https://doi. org/10.1016/j.jcma.2017.07.012

Publisher's Note Springer Nature remains neutral with regard to jurisdictional claims in published maps and institutional affiliations. 